\title{
The Colonization Thesis: Habermas on Reification
}

\author{
Timo Jütten (University of Essex) \\ Note: this is a near-final draft of the paper published in the International Journal of \\ Philosophical Studies 19:5 (2001): 701-27.
}

\begin{abstract}
1. Introduction
Jürgen Habermas' Theory of Communicative Action (henceforth TCA) was published thirty years ago, in 1981. In this paper I argue that its fundamental diagnostic thesis, which I shall call the colonization thesis, remains compelling and should be central to critical theory today. In a nutshell, Habermas conceives of the TCA as a reformulation of Lukács' theory of reification (TCA I, 399), and, according to the colonization thesis, reification is a social pathology that arises when the communicative infrastructure of the lifeworld is 'colonized' by money and power.
\end{abstract}

Unfortunately, the TCA has not received as much attention as it deserves as a theory of reification. ${ }^{1}$ Instead, discussion has more often focused on Habermas' ambitious concept of communicative action, his attempt to fuse hermeneutic and functionalist approaches in social theory, and the charge that he gives up on the emancipatory intent of critical theory. ${ }^{2}$ Moreover, Habermas' own work since 1981 has shifted away from the diagnosis of social pathologies and toward questions of justification in ethics, political philosophy and legal theory, culminating in the publication of Between Facts and Norms (henceforth BFN) in 1992.3 However, this shift does not render the earlier diagnosis obsolete. To be sure, in $B F N$ Habermas retracts his particular claim that juridification in the context of social-welfare legislation is the 'model case' of reification (TCA II, 322), because he no longer believes that juridification is necessarily dilemmatic. ${ }^{4}$ Nevertheless, he remains committed to the general diagnosis of colonization. Asked about the consequences of the recent financial crisis, Habermas insists that ' $[t]$ he whole program of subordinating the lifeworld to the imperatives of the market must be subjected to scrutiny.'5 
The real problem with the colonization thesis is that it is incomplete. Habermas offers a functionalist explanation of reification, but his normative criticism of reification remains largely implicit. In particular, Habermas never explains what is wrong with reification from the perspective of the people whose social relations are reified. The problem with this focus on functionalist explanation is that it is essentially incomplete. It is impossible to explain why reification effects result from the juridification of communicatively structured domains of action but not from the commodification of labour power (as Habermas claims in $T C A$ ), unless one takes into account the normative expectations of the people concerned. If this is right, then the answer to the question of why reification occurs is much more complex than Habermas' functionalist explanation of it suggests.

I will begin my argument with brief sketches of Habermas' criticism of Lukács, which explains why he felt that he had to reformulate reification, and his two-level concept of society, which is the framework for this reformulation (§§2-3). Next, I will discuss the colonization thesis and Habermas' discussion of interchange relations between lifeworld and system, which is the basis of the functional explanation of reification (§§4-5). In the remainder of the paper I will criticise Habermas' functionalist explanation and discuss the commodification of labour and the juridification of social-welfare provision respectively (§§6-8). I conclude that Habermas' theory of reification remains compelling, if his normative account of why reification is wrong from the perspective of the people whose social relations are reified is made explicit (§9).

\section{From Lukács to Habermas}

According to Lukács' analysis of reification in History and Class Consciousness (HCC), social relations between people become reified, or 'take on the character of a thing' (HCC, 83), when labour is commodified and market exchange is institutionalized as the principal form of need satisfaction in society. ${ }^{6}$ As a result, people come to conceive their own and others' abilities and powers (particularly their labour power) as commodities to be bought 
and sold on the market.7 Moreover, Lukács fuses this Marxian analysis with Weber's rationalization thesis and suggests that eventually social institutions like the modern bureaucracy and the legal system (and even modern science) will come to be shaped by the same principles of predictability, calculability and formality that dominate the economic sphere. As a result, Lukács argues, people come to see these institutions as a thing-like 'second nature' (HCC, 86), which appears natural and immutable, and this informs their relationship to the world. In particular, Lukács suggests that people adopt a 'contemplative stance', a passive relationship of contemplation to the social and natural world, in which individuals have lost control over their environment and merely conform to the demands that this environment places upon them $(H C C, 89)$.

Lukács' theory of reification combines an explanatory account of why reification occurs with a convincing phenomenology of its effects. As Axel Honneth has pointed out in a recent study, Lukács' work remains of interest to modern critical theorists because it often grasps social processes in a phenomenologically correct way. ${ }^{8}$ Moreover, while Lukács initially introduces reification as a descriptive concept, in the course of his argument it becomes a normative concept as well. As Honneth also notes, Lukács implicitly contrasts reified social relations with a normative vision of non-reified social relations and, therefore, his theory of reification is a normative critique, as well as an explanation of it. ${ }^{9}$ Lukács argues that reification is some kind of normative wrong, and $H C C$ is an attempt to think through the processes, which Lukács thought to be immanent in capitalism, that will make possible a social transformation and overcome reification. ${ }^{10}$

Needless to say, Habermas' reformulation of reification starts from very different premises, and in the fourth chapter of TCA he subjects Lukács to thorough criticism. In particular, he argues that Lukács' critique of the commodification of social relations and the (formal) rationalization of all areas of life, appeals to the idea of a 'totality of a rationally organized life-context and uses it as a standard for the irrationality of societal 
rationalization' (TCA I, 357). As a result, Lukács could conceive of the overcoming of reification only as a revolutionary act on the part of the proletariat that overcomes capitalism and institutes 'rational life-relations' (TCA I, 363) that would reconcile the social totality. By contrast, Habermas believes, with Weber, that the differentiation of cultural value spheres in the process of social rationalization is irreversible (TCA I, 357) and, moreover, that this differentiation first enables these spheres to develop according to their own inner logic. However, despite his objections to Lukács, Habermas remains convinced of the importance of reification as a concept for social criticism; hence his intention to 'take up the problematic of reification again' and to 'reformulate it in terms of communicative action, on the one hand, and of the formation of subsystems via steering media, on the other' (TCA I, 399), that is, in terms of his two-level concept of society. ${ }^{11}$

\section{Lifeworld and System}

In his two-level concept of society Habermas attempts to grasp the social evolution of modern capitalist societies. ${ }^{12}$ He suggests that these societies must be conceived simultaneously as lifeworlds and systems (TCA II, 118)..$^{13}$ The lifeworld is the "horizon within which communicative actions are "always already" moving', 'a culturally transmitted and linguistically organized stock of interpretive patterns', which frames everyday communication (TCA II, 119, 124). In addition to cultural reproduction, the lifeworld also secures the social integration and socialization of its members on the basis of communicative action. Taken together, these functions of communicative action ensure the symbolic reproduction of the lifeworld (TCA II, 137-38). According to Habermas' theory of social evolution, in the course of social rationalization traditional forms of life are dismantled as more and more interaction contexts come under conditions of rationally motivated mutual understanding, that is, of consensus formation that rests in the end on the authority of the better argument' (TCA II, 145).${ }^{14}$ As a result, the structural components of the lifeworld, culture, society, person, become differentiated and uncoupled from one another, meaning that the institutions of society become independent of worldviews, interpersonal 
relationships become independent of social ones and personal identities become more reflective and less dependent upon tradition. At the same time, form and content become differentiated within the structural components of the lifeworld, as the traditional content of culture becomes differentiated from the formal norms and procedures it embodies, law and morality become differentiated within the society, and cognitive structures are increasingly differentiated from the content of cultural knowledge. Finally, the functional requirements of the reproduction of the lifeworld, such as cultural transmission, social integration and child rearing, are professionalized (TCA II, 146).

The problem with the lifeworld perspective is that it filters out the functional interconnections that help to maintain society through the stabilization of unintended action consequences, such as markets (TCA II, 150). By contrast, systems theory focuses on system integration, understanding society as a self-regulated system modelled on living organisms. According to Habermas, as the lifeworld is differentiated in the process of social rationalization, the complexity of the system also grows, and functional interconnections and dependencies across action contexts become more complex. At the same time, system and lifeworld become uncoupled from one another, and 'system mechanisms get further and further detached from the social structures through which social integration takes place...' In a formulation that echoes Lukács, Habermas writes that in modern societies

[Systemic interconnections] are consolidated and objectified into norm-free structures. Members behave toward formally organized action systems, steered via processes of exchange and power, as toward a block of quasi-natural reality; within these media-steered subsystems society congeals into a second nature. (TCA II, 154) In particular, action oriented toward mutual understanding is replaced by strategic action when 'economic and bureaucratic spheres emerge in which social relations are regulated only via money and power' (TCA II, 154). To be sure, these economic and bureaucratic subsystems are institutionalized in the lifeworld through the creation of appropriate roles and action orientations on the part of its members, but within these formally organized 
domains of action communicative action looses its integrative function and is replaced by delinguistified steering media. As Habermas also puts it, social integration is replaced by system integration. ${ }^{15}$

At this stage in the argument a dialectic of enlightenment becomes apparent in Habermas' argument. ${ }^{16}$ On the one hand, the rationalization of the lifeworld represents an increase in rationality. Unquestioned traditions are overcome, social relations based on privilege are put into question, and the reflective capacities of individuals increase. On the other hand, this rationalization imposes a burden on modern individuals. As traditional forms of knowledge and authority loose their power over people, social integration must be achieved through mutual understanding in language, which is both more time consuming and more prone to disagreement and therefore failure than reliance on tradition. On the one hand, the rationalization of the lifeworld first makes possible the displacement of the material reproduction of the lifeworld into media-steered subsystems (TCA II, 173, 179), and the evolutionary value of this differentiation is an increase in the steering capacity of society. Moreover, in highly differentiated modern societies delinguistified media are 'relief mechanisms' for the overburdening demands on communicative action (TCA II, 181). On the other hand, 'the irony of the world-historical process of enlightenment becomes evident: the rationalization of the lifeworld makes possible a heightening of systemic complexity, which becomes so hypertrophied that it unleashes system imperatives that burst the capacity of the lifeworld they instrumentalize' (TCA II, 155, cf. 283). In Habermas' colonization thesis this dialectic becomes explicit. ${ }^{17}$

\section{The Colonization Thesis}

In TCA Habermas offers an original theory of reification that aims to explain the social pathologies of advanced capitalist societies. According to this theory, reification is the result of the 'colonization of the lifeworld' by the systemic imperatives of the economic and administrative subsystems of society. ${ }^{18}$ This is the colonization thesis: 
In the end, systemic mechanisms suppress forms of social integration even in those areas where a consensus-dependent coordination of action cannot be replaced, that is, where the symbolic reproduction of the lifeworld is at stake. In these areas, the mediatization of the lifeworld assumes the form of a colonization. (TCA II, 196)

The explanation of reification as the result of colonization gives Habermas a criterion for the empirical diagnosis of reification phenomena:

The conversion to another mechanism of action coordination, and thereby to another principle of sociation, results in reification - that is, in a pathological de-formation of the communicative infrastructure of the lifeworld - only when the lifeworld cannot be withdrawn from the functions in question, when these functions cannot be painlessly transferred to media-steered systems of action... (TCA II, 375)

Habermas believes that the colonization thesis is better suited to explain reification than Lukács' theory of reification in History and Class Consciousness, because in his theory 'phenomena of reification lose the dubious status of facts that can be inferred from economic statements about value relations...[but] now make up instead an object domain for empirical inquiry. They become the object of a research program.' I believe that Habermas is right to reformulate the critique of reification in such a way that it can be diagnosed empirically in particular areas of the lifeworld, rather than conceptually in all social relations.

The problem with this argument, I shall argue, is that it only provides a functionalist explanation of reification, while the normative criticism and phenomenology remain largely implicit. By this I mean that Habermas' theory of reification does not explain how members of the lifeworld can understand reification as a normative wrong and how they experience it. As Maeve Cooke has pointed out, critical theorists are in danger of ethical authoritarianism, and in order to avoid it, must make the validity of their claims 'dependent on the reasoning of concrete human agents in historically specific socio-cultural contexts.' In particular, critical theorists avoid ethical authoritarianism if they pay attention to 'deep-seated normative intuitions and expectations that are held to shape individual and collective 
identities in the socio-cultural context that is the focus of their critique' and formulate the normative standards of their critique in relation to them ${ }^{19}$, and that is what Habermas should do. In other words, I argue that his theory of reification remains incomplete. Fortunately, I believe that it is possible to make the implicit normative commitments of the $T C A$ explicit (§6) and to add a plausible phenomenology of reification (§§7-8).

Habermas sees the colonization thesis as the 'second attempt to appropriate Weber in the spirit of Western Marxism' (TCA II, 302). Like Lukács' first attempt, it recasts Weber's diagnosis of the times, which diagnosed a loss of freedom and a loss of meaning, in the light of Marx's critique of capitalist society. As we have seen, Lukács had based his critique of reification on Marx's analysis of the commodification of labour. He had reinterpreted Weber's thesis that modern bureaucratization necessarily results in a loss of freedom because purposive rationality becomes detached from substantive values as a claim about the role of the bureaucracy and modern law in modern capitalist societies. In particular, he argued that the principles of calculability, predictability and formality, which have come to dominate the legal system, mirror the needs of the capitalist economy.$^{20}$ At the same time, he had interpreted Weber's thesis that the differentiation of cultural value spheres necessarily results in a loss of meaning because there remains no unified ethical substance as a claim about the disintegration of the social totality governed by substantive reason into partial systems held together by the formal rationalities that govern each system. ${ }^{21}$

Habermas qualifies both Marx's analysis of the commodification of labour and Weber's analysis of social rationalization. He argues that Marx neither distinguishes sufficiently between the evolutionary value of system differentiation and its class-specific institutionalization that leads to the exploitation of workers nor between the destruction of traditional lifeworlds in the course of social evolution and the reification of post-traditional lifeworlds. Finally, he criticizes Marx for his one-sided focus on the commodification of labour power and suggests that both bureaucratization and monetarization of both public 
and private spheres of life can have reification effects (cf. TCA II, 338-43). At the same time, he qualifies Weber's analysis of bureaucratization and argues that the neutralization of vocational-ethical attitudes and the replacement of ethics by law is an evolutionary advance and represents an increase in rationality that only sometimes leads to a loss of freedom (TCA II, 318). Habermas also qualifies Weber's analysis of the differentiation of cultural value spheres and argues that the rationalization of worldviews and the disintegration of a unified ethical order of life only sometimes lead to a loss of meaning. Taken together, these criticisms of Marx and Weber enable Habermas to conceive of reification as the result of a specific form of the mediatization of the lifeworld, namely, its colonization, which leads to a loss of freedom and a loss of meaning. The task of critical theory then becomes 'to locate, at least in analytical terms, the threshold at which the mediatization of the lifeworld turns into its colonization' (TCA II, 318).

\section{Interchange Relations between Lifeworld and System}

Habermas solves this normative task ${ }^{22}$ through a functionalist analysis of the interchange relations that obtain between the institutional orders of the lifeworld and the media-steered subsystems. According to his theory of social evolution, private and public spheres of social integration are formed in the lifeworld in response to social differentiation. The institutional core of the private sphere is the family, while that of the public sphere comprises the 'cultural complex' and the mass media. ${ }^{23}$ Taken together the private and public spheres are the spaces in which lifeworld members are socialized and in which it is reproduced culturally and socially. The interchange between these lifeworld spaces and the media-steered subsystems takes place through the social roles that lifeworld members assume in their interaction with the economic and bureaucratic spheres. Habermas discusses four such roles: the employee, the consumer, the client and the citizen. The employee and client roles are constituted in legal form and depend upon specific organizations in formally organized domains of action, such as employers in the economic system or social welfare agencies in the administrative system. Assuming these roles, people 'detach themselves from lifeworld contexts and adapt 
themselves to formally organized domains of action' (TCA II, 321). By contrast, the consumer and citizen roles are not dependent upon formally organized domains of action though they do interact with them. They cannot be abstracted from lifeworld contexts in the same manner as the roles of employee and client, because consumers and citizens acquire their preferences, values and attitudes in self-formative processes that are inextricably tied to lifeworld contexts and cannot be detached from them. As Habermas points out, this is why bourgeois ideals 'attach principally to these roles' (TCA II, 322).

For present purposes the roles of employee and client are decisive. According to Habermas, whenever the lifeworld must adapt itself to steering media, the lifeworld 'products' must be able to be 'abstracted, in a manner suitable to the medium in question' (TCA II, 322) in order to be fed into the system. Thus labour must be reconceived as abstract labour, in order to be exchanged for wages. ${ }^{24}$ As Habermas notes, 'viewed historically, the monetarization and bureaucratization of labour power and government performance is by no means a painless process', because it results in the destruction of traditional forms of life. Countless social struggles against urban proletarization, the absolutist state, taxation, trade regulations and so forth testify to the resistance people put up against these challenges of social modernization. Nevertheless, Habermas suggests, the capitalist system and the modern state have gained 'wide acceptance and considerable permanence on the strength of their greater efficiency and superior level of integration' (TCA II, 321). More specifically, In the social-welfare state, the roles provided by the occupational system become...normalized...the burdens resulting from the character of heteronomously determined work are made at least subjectively bearable - if not through "humanizing" the work place, through providing monetary rewards and legally guaranteed securities...The role of employee loses its debilitating proletarian features with the continuous rise of the standard of living... (TCA II, 349)

By contrast, Habermas suggests that the client role is under pressure in advanced capitalist societies. In fact, the abstraction process required for the receipt of welfare state benefits is 
even the model case for the colonization of the lifeworld that is behind the reification phenomena in advanced capitalist societies. It sets in when the destruction of traditional forms of life can no longer be offset by more effectively fulfilling the functions of society as a whole' (TCA II, 322). The problem with the welfare state is that its mechanisms encroach upon the symbolic reproduction of the lifeworld, its cultural reproduction, social integration and the socialization of its members.

\section{From Functionalist Explanation to Normative Criticism}

According to Habermas, the commodification of labour has been normalized to such an extent that it does no longer give rise to reification effects, while the juridification of communicatively structured domains of action is the 'model case' of colonization and, therefore reification in modern capitalist societies. Before I examine this thesis in depth (§§7-8), I will argue that Habermas' functionalist explanation of reification is essentially incomplete and needs to be complemented with a normative account of the legitimate expectations that members of modern capitalist societies have about the organisation of their societies.

To begin with, let me clarify further why Habermas' explanation of reification is functionalist. As we have seen, Habermas argues that mediatization turns into colonization when 'systemic mechanisms suppress forms of social integration even in those areas where a consensus-dependent coordination of action cannot be replaced, that is, where the symbolic reproduction of the lifeworld is at stake' (TCA II, 196, emphasis mine). ${ }^{25}$ The phrase 'cannot be replaced' in this passage raises a functionalist claim: the proper functioning of the lifeworld depends upon its symbolic reproduction through the medium of communicative action. If the symbolic reproduction of the lifeworld is disturbed, crisis phenomena or pathologies are the result. Earlier in TCA, Habermas had discussed the relationship between (i) the contributions that processes of symbolic reproduction make to the maintenance of the structural components of the lifeworld, (ii) the role of communicative action as action 
oriented toward mutual understanding in these reproduction processes and (iii) the crises that result from disturbances in these processes (TCA II, 140-48). For example, social integration is a reproductive process that maintains the legitimacy of interpersonal relations in society (a structural component of the lifeworld), it is achieved through the coordination of action through the medium of intersubjectively recognised validity claims (a function of action oriented toward mutual understanding), and anomie (a crisis) results if this reproductive function is disturbed. In his discussion of reification Habermas returns to this analysis. The claim is that the mediatization of the lifeworld turns into colonization when steering media, such as power and money, encroach upon these processes of symbolic reproduction.

This explanation of colonization is functionalist, then, because the threshold at which mediatization becomes colonization is determined with reference to the functioning or malfunctioning of the symbolic reproduction of the lifeworld. Since Habermas sees reification as the direct result of colonization, its explanation is functionalist, too. The problem with this explanation is that there is no direct inference from a malfunction in the symbolic reproduction of the lifeworld (or indeed from any social malfunction) to a normative wrong to any member of said lifeworld. As Axel Honneth points out, Habermas' argumentative strategy 'implicitly loads these functionalist distinctions with a normative burden of proof that they cannot possibly shoulder. The question concerning the point at which objectifying attitudes unfold their reifying effects cannot be answered by speaking of functional requirements in an apparently non-normative way. ${ }^{26}$ I think that Honneth is right but, unfortunately, he does not explain either what kind of normative explanation is required. Habermas must explain how the functionalist explanation of a social malfunction offered by the critical social theorist is related to the experience of a normative wrong on the part of members of the lifeworld. In my view, he does not explain this relationship clearly enough. 
The most intuitive way of explaining this relationship is to appeal to the normative constitution of the domain of communicative action itself: actors engaging in communicative action always already make idealizing presuppositions about the commitments that they and their interaction partners undertake in communication, and the colonization of such an action domain by money and power makes it impossible to realize this normative content that is implicit in communicative action. However, while this suggestion may provide a normative standard for the wrongness of reification, it does not explain how actors access his standard or how they experience colonization as a normative wrong. Such a concrete account of the phenomenology of reification is still outstanding.

Habermas also analyses the reification that results from the colonization of the lifeworld in terms of Weber's theses of the loss of freedom and the loss of meaning. ${ }^{27}$ Could they be the normative criteria that he needs? Having criticized Weber's original formulations of these theses (cf. TCA I, 244-54), he suggests that the constraints generated by the adaptation of private ways of life to organized labour relations (becoming and employee) and the adaptation of shared forms of life to the directives of juridically organized organizations (becoming a client of the welfare state) constitute a loss of freedom (TCA II, 323), which can be described as the 'systematically induced reification of communicatively structured domains of action' (TCA II, 351-52). Habermas also suggests that the colonization of the lifeworld constitutes a loss of meaning, which manifests itself in problems of orientation in the private sphere, because lifestyles become either one-sidedly instrumental or one-sidedly aesthetic (Weber's famous specialists without spirit and sensualists without heart). At the same time, it leads to a loss of legitimacy in the public sphere, because the rationalization of bureaucratic procedures removes ethical considerations from political decision-making (TCA II, $323-25) . .^{28}$

The problem with these analyses, regardless of their empirical accuracy, is that the loss of freedom and/or meaning can serve as a normative criterion for the wrongness of reification 
only if a conception of freedom and/or meaning can be specified in comparison to which colonization leads to a loss. In particular, reification phenomena should be understood as the result of the disappointment of legitimate expectations. ${ }^{29}$ The loss of freedom and/or meaning is a normative wrong only if there are good reasons why people who suffer it should be disappointed. It is then that social relations come to be seen as thing-like and immutable, and that people can no longer recognise themselves in their social and political institutions. Unfortunately, Habermas never offers an argument along those lines. To see this, consider next the two cases of mediatization that Habermas discusses in TCA, the commodification of labour power and the juridification of social-welfare provision.

\section{Money, Power and the Commodification of Labour}

I believe that Habermas' contrast between the employee and the client roles is very instructive, because it highlights some of the implicit premises of his theory of reification. Apparently, Habermas believes that the problem of alienated labour that is central to Marx and Marxists like Lukács plays much less of a role in advanced capitalist societies. However, there is a tension in TCA between two different explanations Habermas gives for why this is so. On the one hand, Habermas suggests that processes of the material reproduction of society 'sometimes' can be differentiated out of the lifeworld via steering media without pathological side effects, while processes of symbolic reproduction cannot. On the other hand, he suggests that the conversion of concrete into abstract labour eo ipso gives rise to reification effects (TCA II, 375), but, so the suggestion continues, the normalization of the employee role, augmented by secure salaries, social benefits and the promise of social mobility that employees receive for their work in the modern welfare state, somehow neutralises the reification effects that workers experienced during the period of early industrial 'Manchester' capitalism (TCA II, 349). In this section I will argue (a) that the second explanation is right, and (b) that it points to the need for a normative account of reification to complement Habermas' functionalist one. 
(a) The distinction between the material and the symbolic reproduction of society echoes Habermas' earlier discussion of labour and interaction as distinct modes of praxis. ${ }^{30}$ In the context of his two-level concept of society in TCA Habermas re-conceives labour and interaction as two distinct aspects of social reproduction, namely material and symbolic reproduction. Moreover, he argues, through an immanent critique of Talcott Parsons' systems theory, and in particular his theory of steering media, that 'the only functional domains that can be differentiated out of the lifeworld by steering media are those of material reproduction. The symbolic structures of the lifeworld can be reproduced only via the basic medium of communicative action' (TCA II, 261). The argument is that there are differences between money and power, considered as steering media, which explain why the commodification of labour power does not lead to the same pathological effects as the juridification of power in the context of social-welfare legislation.

As I have noted in $\S 3$, steering media replace communicative action in the process of coordinating action. According to Habermas, this replacement 'has the effect of uncoupling interaction from lifeworld contexts' (TCA II, 263). In particular, it relieves actors from the need to take responsibility for their actions, in the sense that actions mediated by steering media do not raise criticisable validity claims.$^{31}$ For instance, in the case of money, agents are able to exchange goods, whereby all involved are committed to the 'generalised' value of utility and the success criterion of profitability, and the exchange is mediated by the empirical motivations of buyer and seller, which determine whether the expected utility and profitability of the exchange justify its occurrence. As Habermas points out, in order to fulfil their function, media must be measurable, alienable and storable. Furthermore, as we have seen, all media must be institutionalized in the lifeworld; in the case of money, this institutionalization takes the form of bourgeois civil law (property and contract).

Next, Habermas compares money to power, considered as a steering medium. He discusses a number of analogies and disanalogies between the two media, but for present 
purposes the decisive disanalogy is that power depends on legitimation in order to be successfully institutionalised. It is not sufficient for power to ensure de facto compliance to commands; rather, the demands of power must give rise to obligations on the part of those commanded, which motivate on the basis of the recognition of normative validity claims..$^{32}$ Again, Habermas' explanation of this disanalogy is instructive.

Whereas the exchange relation does not in its very definition disadvantage anyone involved in his calculation of utility, and whereas the process of exchange may be, as we say, in the interest of both parties, a person taking orders is structurally disadvantaged in relation to a person with the power to give them. (TCA II, 271) The legitimation of power as a medium is necessary because of the structural disadvantage of those subjected to it in relation to those wielding it, and only the appeal to legitimizable collective goals legitimises power. As a result, power is 'less suited for the role of a steering medium designed to relieve us of the burdens and risks of consensus formation in language than is money, which needs no legitimation' (TCA II, 272).

This assumption about the balance of power in the ideal-typical exchange relation is of a piece with Habermas' criticism of Marx, according to which the latter had insufficiently distinguished between the evolutionary value of system differentiation and its class-specific institutionalization that leads to exploitation. He assumes that exchanges between strategically acting individuals are in principle just, unless they are institutionalised in a manner that renders them unjust, for instance, in a class-specific manner that issues in the exploitation of workers. This assumption enables Habermas to infer that money, as a steering medium, needs no legitimation. However, the point of Marx's criticism of capitalism is precisely that the monetarization of labour power and the resulting proletarization of labour necessarily depend upon the existence of a class of people who are forced to sell their labour power in order to survive and therefore suffer collective unfreedom ${ }^{33}$, which renders their position in exchange vulnerable to exploitation. ${ }^{34}$ If this is right, then there is good reason to believe that the monetarization of labour power, which is a necessary condition for 
the differentiating out of the material reproduction of society, is not modelled on the idealtypical exchange relation, and therefore money, as a steering medium, stands in need of legitimation just as much as power does.

(b) In the light of this analysis, Habermas' claim that the employee role has been normalized in the modern democratic welfare state can be understood as a claim about the legitimacy that the employment system has gained as a result of the pacification of class conflict, the welfare state compromise and the secure salaries, social benefits and the promise of social mobility that this compromise has brought about. However, if this is right, then the possibility of differentiating out the material reproduction of society without reification effects is the contingent result of the welfare state compromise and, moreover, cannot be fully explained without reference to the normative expectations of those concerned.

To see this, consider again Habermas' claim that the normalization of the employee role in the course of the twentieth century could compensate employees for the loss of freedom that it originally entailed, while no such compensation is possible for the loss of freedom brought about by the extension of the client role in the modern welfare state. As we have seen, Habermas justifies this contrast with an appeal to the distinction between the different functional necessities of the material and symbolic reproduction of society. Considered from the perspective of the lifeworld this contrast appears in a different light. Now the question is why modern individuals have found the 'compensation' offered in return for 'heteronomously determined work' (TCA II, 349), such as wage increases, job security and conspicuous consumption, acceptable, so that the capitalist welfare state has gained widespread legitimacy. The answer to this question may be much more contingent upon the specific social histories of modern societies than Habermas' functional explanation allows. In the present case, the normalization of the employee role and the pacification of the conflict between labour and capital may rest on some or all of the following legitimate expectations 
on the part of the employees: (i) that continuous economic growth will make possible continuous wage increases which, in turn, will extend possibilities for consumption ${ }^{35}$, (ii) that the maintenance or extension of the healthcare, pension and education systems will guarantee the standard of living of employees and provide educational opportunities for their children, and (iii) that the social system as a whole, in this case the modern capitalist welfare-state, is the best possible system and could be replaced only at the cost of excessive losses of freedom and material wealth on the part of all strata of society. ${ }^{36}$

If this is right, then the pacification of class conflict and the normalization of wage-labour have been and remain contingent upon meeting the legitimate expectations of employees. By the same token, the absence of reification effects due to alienated labour is best explained by the fact that the compensation that employees receive for the performance of their employee roles is in tune with their legitimate expectations. As a result, any changes in the social, political or economic arrangements of society such as a crisis of consumerism, an ideologically motivated crackdown on welfare statism, an economic downturn or a recession have the potential to disrupt the smooth functioning of the employment system and to rekindle the reification effects that accompany the commodification of labour. And the correct explanation for this resurgence of reification will have to appeal to the normative expectations of the employees as much as to the functional necessities of material reproduction.

\section{The Juridification Example}

Habermas believes that the symbolic reproduction of society cannot be differentiated out of the lifeworld, because these reproduction processes constitutively depend upon communicative action. Therefore, he argues, in the second part of his immanent critique of Parsons' systems theory, that the media Parsons postulates for the purposes of social integration ('influence') on the one hand, and socialization and cultural reproduction ('value commitment') on the other, 'fail already at the level of conceptual analysis to satisfy the 
necessary conditions for institutionalization' (TCA II, 273). To begin with, they are not measurable, alienable or storable like money and power. But, more importantly, they have no underlying empirical motivating power and therefore depend upon communicative action oriented toward mutual understanding. Influence and value commitment 'cannot uncouple interaction from the lifeworld context of shared cultural knowledge, valid norms, and responsible motivations, because they remain second-order processes of consensus formation in language' (TCA II, 276). Habermas concludes that there are two types of communicative media, steering media and forms of generalised communication that remain dependent upon lifeworld contexts and consensus formation in language. This explains 'the resistance that structures of the lifeworld offer in certain domains to being converted over from social integration to system integration' (TCA II, 281-82), and also the reification effects that result when the steering media money and power colonize areas of social life that are dependent upon communicative action, because they ensure the symbolic reproduction of the lifeworld.

(a) Habermas considers the juridification (Verrechtlichung) of communicatively structured domains of action in the context of social-welfare provision as an example of such a colonization of the lifeworld that leads to reification effects. ${ }^{37}$ This choice of example seems puzzling at first. After all, the welfare state provides social security to workers in the form of unemployment benefits, health insurance, pension provisions and so forth. As we have seen in $\S 7$, this net of social security is one of the reasons for the normalization of the employee role in modern capitalist societies. However, Habermas believes that social-welfare legislation, despite its freedom-guaranteeing character, also entails a loss of freedom, because it subjects communicatively structured domains of action, such as the family and the school, the sites of socialization, to the systemic imperatives of money and power. How does this happen? 
According to Habermas, the processes of social evolution leading up to modern capitalist societies are accompanied by juridification waves, which lead to the institutionalization of claims and entitlements appropriate to the rational structures of the lifeworld. Thus the first juridification wave legally institutionalizes the two steering media through which the economy and the state administration are differentiated out into subsystems. This includes the creation of bourgeois civil law, which models the relations between strategically acting individuals through the protection of person, property and contract (TCA II, 358). Subsequent juridification waves institutionalize the rule of law with its constitutional principles of life, liberty and property, democratic processes and political rights for all citizens and, finally, the social security guarantees of the modern welfare state. For present purposes the important aspect of these juridification waves is that they legally institutionalize claims and entitlements that are already implicit in the rational structure of the lifeworld and thereby legitimise the social and political order.

[A] lifeworld that at first was placed at the disposal of the market and of absolutist rule little by little makes good its claims. After all, media such as power and money need to be anchored in a modern lifeworld. Only in this way can the bourgeois state gain a nonparasitic legitimacy appropriate to the modern level of justification. Today the structurally differentiated lifeworld, upon which modern states are functionally dependent, remains as the only source of legitimation. (TCA II, 359)

Whereas the 'freedom-guaranteeing' character of the first juridification wave was ambivalent - the transformation of pre-modern relations of power and dependence (between serfs and their lords) into modern relations governed by civil law (between workers and capitalists) increased the freedom of the workers but also forced their proletarization - the next two waves were unambiguously freedom-guaranteeing (TCA II, 361)..$^{8}$ However, with the forth juridification wave, which institutionalizes the modern welfare state, the 'ambivalence of guaranteeing freedom and taking it away' returns. 
While social-welfare guarantees such as those governing limitations on the working hours of employees, their freedom to organise in unions and to bargain for wages and so forth protect the freedoms of employees in domains of action that are already formally organised $^{39}$, other social-welfare guarantees offered by the modern welfare state undermine freedom, because they require 'restructuring interventions in the lifeworlds' of those entitled to assistance. Here, reification effects result from the 'bureaucratic implementation and monetary redemption of welfare entitlements', in particular the 'redefinition' of everyday situations in terms of legal conditions. Thus claims to assistance must be formulated as 'individual legal entitlements', but this 'individualizing definition of, say, geriatric care has burdensome consequences for the self-image of the person concerned, and for his relations with spouse, friends, neighbors, and others; it also has consequences for the readiness of solidaric communities to provide subsidiary assistance' (TCA II, 362).

Habermas maintains that the bureaucratic approach to welfare assistance as legal entitlement subjects its recipients to 'structural violence' when their needs, which are embedded in concrete life situations, are treated as specific cases to which general administrative laws must be applied (TCA II, 363). Moreover, the monetary compensation offered by the welfare state is often inadequate to the specific needs of the individual. However, the therapeutic assistance offered in addition to monetary compensation does not solve the problem either, because it reproduces dependence and reliance on the welfare system whereas the point of therapy is the independence and self-reliance of the individual. Thus the more assistance the welfare system offers to its clients, the more core areas of the lifeworld are bureaucratized and monetarized.

The dilemmatic structure of this type of juridification consists in the fact that, while the welfare-state guarantees are intended to serve the goal of social integration, they nevertheless promote the disintegration of life-relations when these are separated, through legalized social intervention, from the consensual mechanisms that 
coordinate action and are transferred over to media such as power and money. (TCA II, 364)

Habermas is particularly interested in the way in which legal norms redefine spheres of the lifeworld in which he finds 'prior to any juridification, norms and contexts of action that by functional necessity are based on mutual understanding as a mechanism for coordinating action.' Here, his examples are family law and school law. The claim is that social interaction in the family and the school, child rearing and teaching, 'must be able to function independent of legal regulation' (TCA II, 369, emphasis mine). If they are converted to the medium of law, functional disturbances arise: the status of the 'must' in this passage is again functionalist rather than normative.

(b) Again, I believe that Habermas' analysis remains incomplete, because it limits itself to functionalist considerations and does not make explicit the normative expectations of modern individuals concerning the organisation of social-welfare provision, the family and the school. To begin with, consider again the case of an elderly person in need of geriatric care. Habermas explains the problem of juridification in this passage:

The situation to be regulated is embedded in the context of a life history and of a concrete form of life; it has to be subjected to violent abstraction, not merely because it has to be subsumed under the law, but so that it can be dealt with administratively. The implementing bureaucracies have to proceed very selectively and choose from among the legally defined conditions of compensation those social exigencies that can at all be dealt with by means of bureaucratic power exercised according to law. (TCA II, 363)

On the assumption that Habermas is right about the 'violent abstraction' necessitated by bureaucratic social-welfare provision and about the pathological side effects (in particular, alienation, anomie and the unsettling of collective identities ${ }^{40}$ ) experienced by the people concerned and their relations, the question remains what kind of wrong is at issue here..$^{41}$ 
On the face of it, Habermas' criticism could be mistaken for nostalgia, mourning a bygone area in which social relations, for example those between the generations, were more immediate and social assistance, for example to elderly relatives, was organized by families and spouses themselves, assisted by friends and neighbors. Of course, this is not Habermas' point. Rather, he must believe that there are more appropriate forms of organising geriatric care than those of the welfare bureaucracy, and he must believe that people in modern capitalist societies have the legitimate expectation that they and their relations will be better cared for. It is only against the background of such legitimate expectations that present practices fall short. The losses of freedom and meaning that are expressed in reification effects (in alienation from social and political institutions which seem thing-like and immutable, rather than expressing citizens' own values and commitments, for example) can be understood as such only in comparison to those legitimate expectations, which serve as the normative standard against which present practices are evaluated. ${ }^{42}$

If this is right, then Habermas' functionalist explanation of reification in the area of social-welfare provision remains incomplete, because it does not explain why the bureaucratic implementation and monetary redemption of welfare entitlements is experienced as disappointment (and, therefore, gives rise to reification effects) in the first place. Again, there is no direct route from a social malfunction to a normative wrong. It is only when the social malfunction frustrates legitimate expectations that reification effects occur.

A similar argument holds for the case of the juridification of the family and the school. According to Habermas, since these institutions functionally depend on norms and contexts of action based on mutual understanding, their juridification constitutes a 'superimposition of legal norms' on communicative practices, which converts them to the medium of law. Since socialization in the family and the pedagogical process of teaching in the school are formative processes of symbolic reproduction, their conversion to steering media, such as 
law, leads to functional disturbances (TCA II, 369). On the assumption that Habermas is right about the negative side effects of juridification on the family and the school, what kind of wrong is at issue here?

In my view, the criterion for what counts as good socialization or education is immanent to the discourse in the lifeworld that articulates the normative expectations of lifeworld members, and it is impossible to characterize it externally. As a result, the diagnosis of reification effects begins with a hermeneutic understanding of these normative expectations and cannot proceed without taking account of them. At some points in his discussion, Habermas seems to recognise this. Thus, discussing a suggestion to 'dejudicialize' family conflicts, he writes

The juridification of communicatively structured areas of action should not go beyond the enforcement of principles of the rule of law, beyond the legal institutionalization of the external constitutions of, say, the family or the school. The place of law as a medium is to be taken by procedures for settling conflicts that are appropriate to the structures of action oriented by mutual understanding - discursive processes of will-formation and consensus-oriented procedures of negotiation and decision-making' (TCA II, 370-71).

However, this suggestion remains ambivalent, because the appropriateness of discursive processes of will-formation and consensus-oriented procedures of negotiation and decisionmaking can be understood functionally or normatively. In the former case, the argument is that the family and schools must be organised through communicative action because their functioning depends upon it. In the latter case, the argument is that there is something about our concept of what a family is and how it ought to be organised that speaks against juridification. The same holds for our concept of what education is and how it ought to be organised. As Habermas points out, there is a real conflict between a 'strictly pedagogical approach to instruction' and 'the economic system-imperative to uncouple the school system from the fundamental right to education and to close-circuit it with the employment system' 
(TCA II, 371). And this is nothing but a normative struggle about the form, scope and value of education in our societies. If reification effects result from the juridification of education, then this is a sign of normative disappointment and not only of a social malfunction.

\section{Conclusion}

The colonization of the lifeworld by money and power remains a pressing problem in modern societies - and in Habermas' critical theory. However, the shift to questions of justification in $B F N$ has shifted the perspective from the social-theoretical explanation of social pathologies to the philosophical justification of legitimate social relations. And this shift has affected Habermas' view of juridification. He no longer believes that the structure of social-welfare juridification is necessarily dilemmatic, because the criterion by which we can distinguish between freedom-guaranteeing welfare measures and those measures that undermine freedom is not arbitrary. Rather, the relationship between public and private autonomy, which is the basis of the discourse theory of law (BFN 99-104), provides an intuitive normative standard by which the freedom-guaranteeing or -undermining character of juridification can be judged. Social-welfare legislation aimed at the compensation of inequalities 'proves to be paternalistic if it is insensitive to the freedom-restricting side effects of the state's compensations for those inequalities' (BFN 417).43 This is surely correct, but it does not affect the diagnostic claim of the colonization thesis, according to which reification effects arise if the juridification and commodification of communicatively structured domain of action does not meet the legitimate expectations of citizens. There is a clear difference between "differences between norm and reality" that characterise the political experience of citizens in all societies $(B F N 322)^{44}$ and the experience of reification, where serious social pathologies result, because normative resources of the lifeworld have been permanently depleted by juridification and commodification. In other words, the diagnosis of the $T C A$ and the constructive arguments of $B F N$ operate on different levels of analysis. They complement each other. 
This complementarity of social-theoretical diagnosis and normative justification is a hallmark of critical theory in the Frankfurt School tradition. In this paper I have argued that the central diagnostic thesis of the TCA, the colonization thesis, remains compelling if its normative dimension is rendered explicit, and I have tried to do just that. While the concept of reification has nearly disappeared from Habermas' vocabulary, the phenomenon that it characterises is still with us, and therefore critical theory cannot afford to leave it behind. 45

\section{Endnotes}

${ }^{1}$ There are some discussions of Habermas' conception of reification, but few of them are sympathetic. See Horowitz 1998, Morris 1998, and Cook 2004: ch. 2.

${ }^{2}$ See, for example, the contributions in Honneth and Joas 1991, which remains very valuable in the evaluation of TCA.

3 This shift has been foreshadowed in the reception of Habermas' work before the publication of Between Facts and Norms, but has accelerated since. See Baynes 1992, who discusses Habermas in the context of Kant and Rawls. Chambers 1996 and Regh 1997 follow this path. Recent collections devoted to Habermas' political and legal theory include Rosenfeld and Arato 1998 and Schomberg and Baynes 2002.

The so-called "Rawls-Habermas dispute" (see Habermas 1995; Rawls 1995) has led to more research in this direction. Its status is still debated. See McMahon 2002 and Finlayson 2009.

4 I briefly return to this in $\S 9$.

5 Habermas 2009: 186. See also 2000: 89-103, 1986.

${ }^{6}$ For detailed discussions of Lukács' theory of reification see Arato 1972, Arato and Breines 1979, Feenberg 1981, and Löwy 1979.

7 Lukács' famous description of the journalist best captures this alienated relationship to the self: 'Here it is precisely subjectivity itself, knowledge, temperament and powers of expression that are reduced to an abstract mechanism functioning autonomously and 
divorced both from the personality of their 'owner' and from the material and concrete nature of the subject matter in hand. The journalist's "lack of convictions", the prostitution of his experiences and beliefs is comprehensible only as the apogee of capitalist reification' (1971: 100).

8 Cf. Honneth 2008a: 24.

${ }_{9}$ Cf. Honneth 2008a: 26-27.

${ }^{10}$ To be sure, reification is neither morally wrong nor unjust. Its wrongness is systemic in that it is the result of the system of capitalist social relations, rather than any contingent actions of individual capitalists or bureaucrats acting within the confines of that system. Nevertheless, it is a normative wrong and those suffering from it have good reasons to oppose it because they are suffering from it. While this kind of wrongness might seem suspect to moral philosophers, it is quite common among critical theorists, including Marx.

For an argument to the effect that, according to Marx, workers have the same reasons to struggle against exploitation see Wood 1995 and 2004: 242-64.

${ }^{11}$ For reasons of space I skip Habermas' criticism of Adorno and Horkheimer's conception of reification in the Dialectic of Enlightenment and other works (see TCA I, 36699). While this criticism has been influential, it has been challenged by scholars who are more sympathetic to the first generation of the Frankfurt School than to Habermas (see, for example, Hammer 2000).

${ }^{12}$ To be sure, the two-level concept of society has been subject to criticism from the beginning. In particular, it has been suggested that the distinction is 'indefensible' and rests on an insufficiently radical critique of functionalism (Joas 1991: 98), as a result of which Habermas 'cedes too much territory to systems theory' and thereby gives up the emancipatory commitment of critical theory (McCarthy 1991: 120, 133). However, since Habermas' conception of reification stands and falls with the lifeworld-system distinction, I will grant it here and only criticise it insofar as it impinges on his theory of reification. 
${ }_{13}$ The distinction between lifeworld and system is an analytical distinction that also comes to reflect a real distinction in modern societies (Habermas 1991: 256-58).

14 The rationalization of the lifeworld does not eliminate conflict, it probably increases it, but these conflicts will be transparent, rather than concealed under the veil of ideology.

15 Both Joas and McCarthy have criticized this characterization of the economic and bureaucratic subsystems. In particular, they object to Habermas' alleged attempt to characterize subsystems by the type of rationality that is dominant in them (Joas 1991: 112; McCarthy 1991: 128-29). After all, it is an empirical question which types of rationality are dominant in any given domain of action, and it is therefore impossible to prejudge the answer in theory construction. In response, Habermas has clarified his position: 'It is obvious that commercial enterprises and government offices, indeed economic and political contexts as a whole make use of communicative action that is embedded in a normative framework...my thesis amounts merely to the assertion that the integration of these action systems is in the final instance not based on the potential for social integration of communicative actions and the lifeworldly background thereof' (1991: 257, cf. TCA II, 31011). As he also puts it in relation to the economic and administrative subsystems: 'Strategic actions do not only occur here; and it is not only strategic actions that occur here' (1991: 258).

${ }^{16}$ Here I agree with Honneth, who also has suggested that TCA can be understood as an attempt to explain the diagnosis of the Dialectic of Enlightenment in communicationtheoretical terms (1991: 285).

${ }^{17}$ For a similar account of this 'paradox of modernity' see Cooke 1994: 134-36.

${ }_{18}$ This formulation renders explicit what is already implicit in my discussion of Lukács in §2: 'reification' refers to a process and to the result of that process. See also Honneth 2008a: 53 .

${ }^{19}$ See Cooke (2005: 382-84) for a careful elaboration of this danger of authoritarianism. Cooke believes that Habermas' conception of communicative action is an attempt to avoid 
authoritarianism by grounding normative criticism in the idealizing presuppositions of communication. But it is not clear to me how these presuppositions figure in the experience of actors. See my discussion in $§ 6$.

20 See Lukács 1971: 95-97, 107-109, for his discussion of the relationship between capitalism and law.

${ }^{21}$ For the discussion of the disintegration of the social totality into isolated parts and the emergence of expert cultures see Lukács 1971: 101-107.

22 The determination of the threshold where mediatisation turns into colonization is a normative task on my interpretation, because it is impossible to answer this question on functionalist grounds alone (see §6).

${ }^{23}$ Deborah Cook has criticized Habermas' treatment of the family in this context (2004: 61-66). See also Fraser 1985.

24 The same is true for use-value orientations, which have to be transformed into demand preferences (of customers), and public opinion, which has to be transformed into mass loyalty (of citizens).

25 There are many other passages where Habermas makes the point that communicative action is functionally necessary for the symbolic reproduction of the lifeworld. For a particular strong expression of this point see his discussion of the family and schools: in these spheres of the lifeworld, we find, prior to any juridification, norms and contexts of action that by functional necessity are based on mutual understanding as a mechanism for coordinating action' (TCA II, 369, second emphasis mine). I shall return to this passage at the end of $\S 8(a)$.

${ }^{26}$ Honneth 2008a: 55. Honneth 1991: 292-305 had argued already that the fusion of functionalist and normative considerations is characteristic of $T C A$ as a whole.

${ }_{27}$ This return to the theses of the loss of freedom and the loss of meaning is not surprising. As Jay Bernstein has pointed out, the systematic core of critical theory consists of a concern with the twin problems of domination and nihilism (1995: 21-34), and Weber's 
theses concern these two problems, too. To be sure, Habermas criticises Weber's theses and offers reformulations of them in terms of his own theory, but his concern with them is obvious. I also agree with Bernstein that Habermas focuses his attention on the loss of freedom thesis to the detriment of the loss of meaning thesis (1995: 29).

${ }^{28}$ Habermas' discussion of the loss of meaning is complex, because he distinguishes the phenomena of a loss of orientation and of legitimacy from a more general phenomenon, cultural impoverishment, which results from the disintegration of substantive reason, expressed in religious and metaphysical worldviews. The ensuing differentiation of the value spheres of science, morality and art leads to a dying out of vital traditions, as these spheres increasingly become the preserve of expert cultures, thus depriving the wider lifeworld of a unified and unifying cultural tradition that is kept alive in everyday practices. Habermas denies that cultural impoverishment necessarily follows from cultural rationalization or that it follows from colonization. Rather, he conceives of cultural impoverishment and colonization as two interlocking and mutually enforcing developments (TCA II, 327). Several commentators have questioned this claim. Thus, according to Maeve Cooke, 'Habermas regards the loss of meaning (cultural impoverishment) both as a pathological development that runs parallel to the colonization of the lifeworld and as a social pathology that is caused by colonization of the lifeworld' (1994: 191, n. 59). According to Deborah Cook, the confused relationship between colonization and the loss of meaning comes down to confusion about the relationship between the conditions of reification and its effects, since Habermas argues elsewhere that the emergence of specialized spheres of science, morality and aesthetics is a precondition of colonization (2004: 52; see my discussion in §2). However, neither Cooke nor Cook thematize the distinction Habermas draws between the phenomena of a loss of orientation and of legitimacy and cultural impoverishment.

${ }^{29}$ I cannot offer an exhaustive definition of 'legitimate expectations' here, but clearly people develop expectations on the basis of the explicit and implicit values (concerning rights, deserts and other entitlements) that their social and political institutions embody. 
These expectations are disappointed when social and political change remove the ground, so to speak, on which social cooperation takes place (see also $\S 7(b)$ ).

30 See Habermas 1974. Most commentators see the distinction between labour and interaction at work in the later distinction between strategic and communicative action (Giddens 1982; White 1989: 44-46; Outhwaite 1994: 15-18), but I would argue that the distinction between material and symbolic reproduction better captures Habermas' earlier concerns. For a similar view see Postone 1993: 252, 259-6o.

${ }^{31}$ Habermas initially defines validity claims at TCA I, 38. See also Heath 1998.

${ }^{32}$ Habermas does not defend this claim against the objection that government power and obedience to it could be conceptualised along Hobbesian lines as strategically motivated.

33 I say 'collective' unfreedom because proletarians may be free individually to leave the working class (by becoming petit bourgeois shopkeepers, for example) and thereby to avoid the unfreedom that is constituted by being forced to sell their labour power (Cohen 1982). This does not affect my argument that, structurally, the proletarization of labour leads to unfreedom.

34 See Wood 1995 and 2004: 242-64 for an argument to the effect that the problem with exploitation is that it exploits the vulnerability of a person or a group of people in order to get at some substantive good.

35 Cooke also notes that Habermas' analysis of colonization seems to be tailored to societies which enjoy continuous economic growth (1994: 138).

${ }^{36}$ The last point formulates, in normative terms, Habermas' claim that markets are functionally necessary for the reproduction of modern societies (see, for example, 1990: 11, 16-17). It also offers an explanation of why very few workers in the West were tempted by the Soviet 'alternative'.

37 Habermas thinks that there are no particular problems of method or content in this area, because the sociology of law belongs to the classical research areas of sociology (TCA II, 356). 
He attributes the term juridification to Otto Kirchheimer who uses it in his 1928 doctoral dissertation: 'In all fields of endeavor things are turned into law (Verrechtlichung); all factual decisions involving actual power relations are avoided, whatever the issue: the dictatorial powers of the President of the Reich, or the settlement of labor disputes, or anything else. Everything is formalized juridically and thereby neutralized' (Kirchheimer 1969: 7).

${ }^{38}$ In my view, Habermas' discussion of the first juridification wave is insufficiently critical of the ambivalence he diagnoses. Thus, Habermas twice refers to the forced proletarization of labour brought about by the institutionalization of bourgeois civil law as 'side effects' (TCA II, 361, 362). But if, as I have suggested in $\S 7$, proletarization is a necessary condition for differentiating the economy out of the lifeworld, then its debilitating features for workers can hardly be called side effects. Rather, they are a necessary pathology of capitalism as a social form.

39 As Habermas explains earlier in $T C A$, domains of action are formally organised if they are 'first generated by positive law' (TCA II, 309). See my discussion in $\S 5$.

Of course, the analytic value of this distinction may be questioned if it can be shown either that there is a normative structure inherent in the labour process itself or in the social organisation of labour. See Honneth 1982 and 2008b respectively.

40 Alienation, anomie and the unsettling of collective identities are the manifestations of crisis in the case of disturbances in the social integration of society (see figure 22, TCA II, 143).

${ }^{41}$ And it is far from clear that he is indeed right about them. Thus, according to William Scheuerman, Habermas' 'hostility to formal law' prevents him from seeing that the reification effects he ascribes to the juridification of social-welfare provision might be better explained by the exercise of 'blanket authority' on the part of bureaucratic officials than by the structural violence of formal law (2008: 83-84). 
Moreover, Scheuerman raises a practical objection to Habermas' proposed alternative: 'Habermas still needs to show why his proposal for a relative decentralization of legal authority can grapple with the imposing problem of how inequalities are to be undermined in a particular social sphere so that conflict resolution there will constitute more than a front for the exercise of illegitimate power. What would procedures in the spheres of family life, for example, have to look like so that patriarchal power could be prevented from transforming an (allegedly) democratic procedures-oriented system of conflict resolution into a cruel joke on women?' (2008: 84)

${ }^{42}$ Those legitimate expectations may be fairly indeterminate, but I do believe that they are necessary because in their absence there is nothing to guide social criticism. In this sense critical theory depends on at least a minimal conception of the good. For a similar view see Cooke 2005: 380 .

43 Conceptually, Habermas retracts his distinction between law as a medium and law as an institution, which cannot be upheld from the perspective of citizens as autonomous agents. See BFN 416 and 562 , note 48 .

44 Habermas' discussion of this problem is the only place in $B F N$ where reification is mentioned.

45 I presented a very early version of this paper to the Philosophy and the Social Sciences Colloquium in Prague, May 2009. Thanks to the participants for their helpful comments. Many thanks to Maeve Cooke, Thomas McCarthy, Brian O'Connor and Daniel Steuer. I am particularly grateful to Jürgen Habermas for written comments on an earlier version of the paper.

\section{Bibliography}

Arato, Andrew. 1972. Lukács' Theory of Reification. Telos, 11, 25-66.

Arato, Andrew \& Breines, Paul. 1979. The Young Lukács and the Origins of Western Marxism. London: Pluto Press.

Baynes, Kenneth. 1992. The Normative Grounds of Social Criticism: Kant, Rawls, and Habermas. Albany NY: State University of New York Press.

Bernstein, J.M. 1995. Recovering Ethical Life. Jürgen Habermas and the Future of Critical Theory. London and New York: Routledge.

Chambers, Simone. 1996. Reasonable Democracy: Jürgen Habermas and the Politics of Discourse. Ithaca and New York: Cornell University Press. 
Cohen, G.A. 1982. The Structure of Proletarian Unfreedom. Philosophy and Public Affairs, $12,3-33$.

Cook, Deborah. 2004. Adorno, Habermas, and the Search for a Rational Society. London and New York: Routledge.

Cooke, Maeve. 1994. Language and Reason. A Study of Habermas's Pragmatics. Cambridge MA: The MIT Press.

Cooke, Maeve. 2005. Avoiding Authoritarianism. On the Problem of Justification in Contemporary Critical Social Theory. International Journal of Philosophical Studies, 13, 379-404.

Feenberg, Andrew. 1981. Lukács, Marx and the Sources of Critical Theory. Totowa, NJ: Rowman and Littlefield.

Finlayson, James Gordon. 2009. Not Much Ado About Habermas and Rawls. MS

Fraser, Nancy. 1985. What's Critical About Critical Theory? The Case of Habermas and Gender. New German Critique, 35, 97-131.

Giddens, Anthony. 1982. Labour and Interaction. Pp. 149-61 in J.B. Thomson and D. Held (eds), Habermas: Critical Debates. London: Macmillan.

Grondin, Jean. 1988. Reification from Lukács to Habermas. in T. Rockmore (ed.), Lukács Today. Dordrecht, NL: Reidel Publishing.

Habermas, Jürgen. 1974. Labour and Interaction: Remarks on Hegel's Jena Philosophy of Mind. Pp. 142-69 in J. Habermas, Theory and Practice, trans. John Viertel London: Heineman.

Habermas, Jürgen. 1984. The Theory of Communicative Action, Vol. 1: Reason and Rationalisation of Society, trans. Thomas McCarthy. Boston: Beacon Press.

Habermas, Jürgen. 1986. The New Obscurity: The Crisis of the Welfare State and the Exhaustion of Utopian Energies. Philosophy \& Social Criticism, 11: 1-18.

Habermas, Jürgen. 1987. The Theory of Communicative Action, Vol. 2: A Critique of Functionalist Reason, trans. Thomas McCarthy. Boston: Beacon Press.

Habermas, Jürgen. 1990. What Does Socialism Mean Today? The Rectifying Revolution and the Need for New Thinking on the Left. New Left Review, 3-21.

Habermas, Jürgen. 1991. A Reply. Pp. 214-64 in A. Honneth and H. Joas (eds), Communicative Action: Essays on Jürgen Habermas' The Theory of Communicative Action. Cambridge MA: The MIT Press.

Habermas, Jürgen. 1995. Reconciliation through the Public Use of Reason: Remarks on John Rawls's Political Liberalism. The Journal of Philosophy, XCII, 109-31.

Habermas, Jürgen. 1996. Between Facts and Norms. Contributions to a Discourse Theory of Law and Democracy, trans. Willam Rehg. Cambridge MA: The MIT Press.

Habermas, Jürgen. 2000. The Postnational Constellation, trans. Max Pensky. Cambridge: Polity.

Habermas, Jürgen. 2009. Europe: The Faltering Project, trans. Ciaran Cronin. Cambridge: Polity.

Hammer, Espen. 2000. Minding the World: Adorno's Critique of Idealism. Philosophy and Social Criticism, 26, 71-92.

Heath, Joseph. 1998. What is a Validity Claim? Philosophy and Social Criticism, 24, 23-41.

Honneth, Axel. 1982. Work and Instrumental Action. New German Critique, 26, 31-54.

Honneth, Axel. 1991. The Critique of Power: Reflective Stages in a Critical Social Theory. Cambridge MA: The MIT Press.

Honneth, Axel. 2008a. Reification. A New Look at an Old Idea. Oxford: Oxford University Press.

Honneth, Axel. 2008b. Arbeit und Anerkennung. Versuch einer Neubestimmung. Deutsche Zeitschrift für Philosophie, 56, 327-41.

Honneth, Axel \& Joas, Hans (eds). 1991. Communicative Action: Essays on Jürgen Habermas's The Theory of Communicative Action, Cambridge MA, The MIT Press.

Horowitz, Andrew. 1998. "Like a tangled mobile". Reason and reification in the quasidialectical theory of Jürgen Habermas. Philosophy and Social Criticism, 24, 1-23. 
Joas, Hans. 1991. The Unhappy Marriage of Hermeneutics and Functionalism. Pp. 97-118 in A. Honneth and H. Joas (eds), Communicative Action: Essays on Jürgen Habermas's The Theory of Communicative Action. Cambridge MA: The MIT Press.

Kirchheimer, Otto. 1969. The Socialist and Bolshevik Theory of the State. Pp. 3-21 in F.S. BURIN and K.L. SHELL (eds), Politics, Law, and Social Change: Selected Essays. New York: Columbia University Press.

Löwy, Michael. 1979. Georg Lukács: From Romanticism to Bolshevism. London: New Left Books.

Lukács, Georg. 1971. History and Class Consciousness. Studies in Marxist Dialectics. London: Merlin Press.

McCarthy, Thomas. 1991. Complexity and Democracy: or the Seducements of Systems Theory. Pp. 119-39 in A. Honneth and H. Joas (eds) Communicative Action: Essays on Jürgen Habermas's The Theory of Communicative Action. Cambridge MA: The MIT Press.

McMahon, Christopher. 2002. Why There is No Issue Between Habermas and Rawls. The Journal of Philosophy, XCIX, 111-29.

Morris, Martin. 1998. Capitalist Society and Its Real Abstractions: The Critique of Reification in Habermas's Social Theory. Rethinking Marxism, 10, 27-50.

Outhwaite, William. 1994. Habermas: A Critical Introduction. London and New York: Routledge.

Postone, Moishe. 1993. Time, Labor and Social Domination: A Reinterpretation of Marx's Critical Theory. Cambridge: Cambridge University Press.

Rawls, John. 1995. Reply to Habermas. The Journal of Philosophy, XCII, 132-80.

Rehg, William. 1994. Insight and Solidarity: The Discourse Ethics of Jürgen Habermas. Berkeley CA: The University of California Press.

Rosenfeld, Michel and Arato, Andrew (eds). 1998. Habermas on Law and Democracy: Critical Exchanges. Berkeley CA, University of California Press.

Scheuerman, William. 2008. Frankfurt School Perspectives on Democracy and Law. London and New York: Routledge.

Shomberg, René vom \& Baynes, Kenneth (eds). 2002. Discourse and Democracy: Essays on Habermas's between Facts and Norms. Albany NY, State University of New York Press.

White, Stephen. 1989. The Recent Work of Jürgen Habermas: Reason, Justice and Modernity. Cambridge: Cambridge University Press.

Wood, Allen W. 1995. Exploitation. Social Philosophy \& Policy, 12, 136-58.

Wood, Allen W. 2004. Karl Marx. London and New York: Routledge. 